\title{
LABOR PRODUCTIVITY, WAGE INCREASE AND INFLATION, AN EASTERN EUROPEAN APPROACH
}

\author{
Negrea Adrian ${ }^{1}$ \\ Benea Ciprian Beniam ${ }^{2}$ \\ Săcară Adina Onița ${ }^{3}$
}

DOI: https://doi.org/10.31410/LIMEN.S.P.2019.159

\begin{abstract}
Labor productivity has been the basis for one on one economic wage growth in all developed countries. The paper is analyzing the prospect of measures taken by the European 13 countries that became EU members in 2004, 2007 and 2013 regarding compensation of employees per hour worked expressed in EUR, the evolution of the real labor productivity per hour worked index where $2010=100 \%$ and the impact on inflation expressed in percentage change. For this approach, Eurostat database was consulted and for a better understanding, the study was done for the period of time starting from 2004 for Cyprus, the Czech Republic, Estonia, Hungary, Latvia, Lithuania, Malta, Poland, Slovakia, and Slovenia, from 2007 for Bulgaria and Romania, and from 2013 Croatia. Based on the analysis results, should pinpoint conclusions regarding the evolution of the indicators and the impact that they had on price stability.
\end{abstract}

Keywords: Labor productivity, Wages, Inflation.

\section{INTRODUCTION}

$\mathrm{L}$ abor productivity is an important economic indicator for the business environment and national economies alike, because the wage increase of public and private employees are closely correlated with it. Economists have struggled to connect labor productivity with wage growth through numerous articles and papers examining the connection, trying to give a positive feedback about the struggled relationship between the two indicators. Feldstein M. (2008) highlights that the relation between growth in productivity and the rise of wages for all the workers should be a symmetrical. He states that labor productivity is defined as the output per hour of labor input, i.e. as the average output per unit of labor.

Gordon (1986) started to tap the lack of measures taken by the European governmental institutions and privately owned companies to increase wages and not to fear about the negative aspect of extra inflation with no bonus of extra output. Others like Hellerstein J., Neumark D., Troske K. (1996) tried to correlate the indicators with individual-level data on workers revealing the inputs and the outputs of industry and the changes in earnings. Labor productivity was also on the mind of Biesebroeck Van J. (2003) where a comparison was made between the marginal productivity of different categories of workers with the wages they earn. Faggio G., Salvanes K., Reenen Van J. (2007) got to the conclusion that the diffusion of new technologies and the use of skilled human resources in the technological sector heterogeneously across firms has increased both the spread of productivity and the spread of wages.

\footnotetext{
University of Oradea, Strada Universității nr. 1, Oradea 410087, Romania University of Oradea, Strada Universității nr. 1, Oradea 410087, Romania University of Oradea, Strada Universității nr. 1, Oradea 410087, Romania
} 
More recent studies undertaken by Stansbury A., Summers L. (2017) were focused on the substantial variations in productivity growth that have taken place during recent decades and have been associated with substantial changes in median and mean real compensation; or Lazear E. (2019) thinks that changes in productivity are the outputs of different educational levels being more than sufficient to account for changes in the wage distribution.

Based on the aforementioned theories, the percentage of wage increases must coincide with the percentage of increased labor productivity. If the percentage of wage increases is either higher than the percentage of the increased labor productivity, or is lower, it leaves room for certain discrepancies in the economy, foreseeing either more burden placed on the wage expenses in the total expenses of the private companies or of the state, or the private companies or state institutions have more disposable income for other types of expenses.

Table 1. Real labor productivity per hour worked expressed in \%

\begin{tabular}{|c|c|c|c|c|c|c|c|c|c|c|c|c|c|c|c|}
\hline GEO/TIME & 2004 & 2005 & 2006 & 2007 & 2008 & 2009 & 2010 & 2011 & 2012 & 2013 & 2014 & 2015 & 2016 & 2017 & 2018 \\
\hline Bulgaria & 83 & 87 & 90 & 93 & 95 & 96 & 100 & 105 & 108 & 109 & 110 & 114 & 118 & 120 & 124 \\
\hline Czech Rep. & 86 & 90 & 96 & 100 & 100 & 98 & 100 & 102 & 102 & 102 & 104 & 109 & 108 & 111 & 112 \\
\hline Estonia & 80 & 85 & 89 & 96 & 93 & 95 & 100 & 99 & 102 & 103 & 106 & 105 & 107 & 110 & 117 \\
\hline Croatia & 99 & 102 & 104 & 106 & 105 & 98 & 100 & 104 & 106 & 109 & 107 & 112 & 116 & 117 & 119 \\
\hline Cyprus & 94 & 97 & 101 & 100 & 100 & 99 & 100 & 100 & 100 & 101 & 101 & 102 & 103 & 104 & 104 \\
\hline Latvia & 84 & 91 & 96 & 103 & 94 & 97 & 100 & 104 & 108 & 108 & 111 & 115 & 117 & 123 & 126 \\
\hline Lithuania & 79 & 85 & 92 & 98 & 101 & 96 & 100 & 107 & 109 & 112 & 115 & 114 & 113 & 121 & 123 \\
\hline Hungary & 88 & 93 & 97 & 100 & 102 & 99 & 100 & 103 & 101 & 102 & 101 & 103 & 100 & 103 & 107 \\
\hline Malta & 97 & 96 & 96 & 98 & 98 & 96 & 100 & 102 & 103 & 106 & 111 & 119 & 118 & 122 & 123 \\
\hline Poland & 84 & 85 & 88 & 90 & 91 & 94 & 100 & 105 & 107 & 108 & 110 & 112 & 114 & 119 & 127 \\
\hline Romania & 77 & 81 & 87 & 92 & 103 & 102 & 100 & 104 & 107 & 112 & 116 & 122 & 128 & 135 & 141 \\
\hline Slovenia & 88 & 94 & 99 & 103 & 103 & 97 & 100 & 104 & 103 & 102 & 103 & 104 & 107 & 111 & 114 \\
\hline Slovakia & 81 & 84 & 89 & 95 & 97 & 95 & 100 & 102 & 104 & 106 & 109 & 112 & 113 & 115 & 118 \\
\hline
\end{tabular}

Source: Eurostat

In the case of the above table, the analysis is based on Eurostat data for all the 13 member countries of the European Union that joined since 2004, the data being expressed in percentages, and, the basic year for calculation is 2010. From the table it appears that all countries have registered an increase in labor productivity since 2011, with the exception of Estonia, which in 2011 registered a decline in terms of the analyzed indicator.

If we look closely at the table, we can see a sharp increase in labor productivity since 2010 for a group of states, which at the end of 2018 registered an increase of more than $20 \%$ compared to 2010 . Here we can see how Bulgaria reached $124 \%$, Latvia reached $126 \%$, Lithuania reached $123 \%$, Malta reached 123\%, and Poland reached 127\%.

Romania is the only country with an increase of labor productivity reaching $141 \%$ compared to 2010. It is the largest increase in labor productivity recorded by a country that has recently joined the European Union and is in full process of economic integration. This significant increase may be due to the discrepancies existing between the Eastern and the Western economies in terms of economic development and which achieve greater jumps in labor productivity due to the positive economic measures taken during the post-accession period.

Now that the evolution of labor productivity has been reviewed, a correlation of this indicator with the evolution of the wage increase in the 13 analyzed countries in the table below is being done next. 
The same formula was applied to the evolution of wage increases, namely: based on Eurostat data, all 13 EU member countries that acceded since 2004 were analyzed, the data being expressed in EUR per hour worked.

As can be seen in the table below, all the countries at the time of accession to the European Union recorded depreciated revenues compared to the reference year 2010.

What is interesting, however, is happening around the base year 2010, because at that time the international financial crisis had made its presence felt. The years 2009 and 2011 are years in which in theory the wage incomes per hour worked should decline due to a slowdown in consumption and production, but as shown in the table below, there are countries that defy the crisis and continue the wage increases, these countries being: Bulgaria, Estonia, Cyprus, Malta, Slovenia and Slovakia. The rest 7 countries analyzed recorded a slowdown of the wage income per hour worked, even if it took years for those values to reach the same level of 2008 or slightly higher.

Table 2. Compensation of employees per hour worked expressed in EUR

\begin{tabular}{|l|c|c|c|c|c|c|c|c|c|c|c|c|c|c|c|}
\hline GEO/TIME & $\mathbf{2 0 0 4}$ & $\mathbf{2 0 0 5}$ & $\mathbf{2 0 0 6}$ & $\mathbf{2 0 0 7}$ & $\mathbf{2 0 0 8}$ & $\mathbf{2 0 0 9}$ & $\mathbf{2 0 1 0}$ & $\mathbf{2 0 1 1}$ & $\mathbf{2 0 1 2}$ & $\mathbf{2 0 1 3}$ & $\mathbf{2 0 1 4}$ & $\mathbf{2 0 1 5}$ & $\mathbf{2 0 1 6}$ & $\mathbf{2 0 1 7}$ & $\mathbf{2 0 1 8}$ \\
\hline Bulgaria & 1,7 & 1,9 & 2,0 & 2,3 & 2,6 & 2,9 & 3,2 & 3,4 & 3,7 & 4,0 & 4,2 & 4,4 & 4,7 & 5,2 & 5,7 \\
\hline Czech Rep. & 5,5 & 6,0 & 6,8 & 7,4 & 8,5 & 8,0 & 8,5 & 9,0 & 9,0 & 8,7 & 8,4 & 8,8 & 9,1 & 9,9 & 11,0 \\
\hline Estonia & 4,0 & 4,4 & 5,1 & 6,4 & 7,1 & 7,4 & 7,4 & 7,4 & 8,0 & 8,5 & 9,1 & 9,4 & 10,0 & 10,7 & 12,1 \\
\hline Croatia & 6,7 & 7,2 & 7,4 & 7,8 & 8,3 & 8,2 & 8,3 & 8,4 & 8,5 & 8,4 & 8,0 & 8,4 & 8,5 & 8,7 & 9,0 \\
\hline Cyprus & 12,4 & 13,6 & 14,1 & 13,8 & 13,9 & 14,8 & 14,8 & 15,0 & 15,3 & 14,7 & 14,2 & 13,9 & 13,6 & 13,9 & 14,0 \\
\hline Latvia & 2,8 & 3,4 & 4,2 & 5,7 & 6,3 & 5,7 & 5,3 & 5,4 & 5,9 & 6,3 & 6,7 & 7,4 & 8,0 & 8,6 & 9,3 \\
\hline Lithuania & 3,4 & 3,8 & 4,6 & 5,2 & 5,9 & 5,6 & 5,4 & 5,8 & 6,1 & 6,5 & 6,8 & 7,1 & 7,4 & 8,3 & 8,9 \\
\hline Hungary & 5,9 & 6,5 & 6,5 & 7,3 & 7,9 & 6,9 & 7,1 & 7,3 & 7,3 & 7,2 & 6,9 & 7,0 & 7,0 & 7,6 & 7,9 \\
\hline Malta & 8,5 & 8,3 & 8,6 & 8,9 & 9,2 & 9,4 & 10,0 & 10,6 & 11,0 & 11,5 & 12,0 & 12,7 & 12,7 & 13,1 & 13,4 \\
\hline Poland & 3,7 & 4,2 & 4,5 & 4,9 & 5,7 & 4,8 & 5,7 & 5,8 & 6,0 & 6,1 & 6,2 & 6,3 & 6,3 & 6,9 & 7,5 \\
\hline Romania & 1,8 & 2,6 & 3,0 & 3,5 & 4,3 & 3,7 & 4,1 & 3,9 & 3,9 & 4,1 & 4,4 & 4,5 & 5,1 & 5,8 & 6,5 \\
\hline Slovenia & 10,8 & 11,7 & 12,5 & 13,3 & 14,2 & 14,3 & 14,7 & 15,1 & 15,1 & 15,0 & 15,1 & 15,2 & 16,1 & 16,9 & 17,7 \\
\hline Slovakia & 4,2 & 4,7 & 5,3 & 6,3 & 7,2 & 7,8 & 8,0 & 8,2 & 8,5 & 8,8 & 9,0 & 9,3 & 9,6 & 10,3 & 11,0 \\
\hline
\end{tabular}

Source: Eurostat

If we take a close look at the subsequent evolution of wage incomes per hour worked, we can observe that Cyprus has registered a decline of this indicator. This fact can be attributed to the financial measures on the banking sector in Cyprus by the European Commission, which has led to a severe economic correction, affecting the growth and development for the Cypriot economy.

The rest of the countries, on the other hand, experienced an upward trend in wage incomes per hour worked, even if some countries had a better advance or some countries had a more modest advance, such as Croatia, whose wage income per hour worked only increased less than 1 EUR since 2013, the year of the country's accession to the European Union.

Now, if we are to make a parallel between the percentage of wage increases and the percentage of the increase in labor productivity, we can see that both indicators have registered significant increases, but more evident is the increase of the wage incomes per working hour.

Approximately all the 13 countries analyzed recorded a higher increase in the wage income per hour worked than the percentage of the increase in labor productivity, except for Croatia and Cyprus, where the percentage of the increase in labor productivity was significantly higher than the increase of the wage income per hour worked. 
Bulgaria, Estonia, Latvia, Lithuania, Malta, Slovenia and Slovakia, with the exception of one year, have registered from the reference year 2010 increases in wages per hour worked significantly higher than the percentage of labor productivity's growth. Private companies and state institutions in these countries offered higher wages each year, disregarding economic theories that suggest a correlation of wage increases to labor productivity.

These wage increases also stem from the need to maintain well-skilled workforce in the country of origin to ensure sustainable future economic growth and development, trying to limit the bleeding of human resource exodus towards Western countries.

The other 4 countries analyzed: Czech Republic, Hungary, Poland and Romania, although towards the end of the analyzed period they also have an evolution similar to the other 7 countries mentioned above, in the sense that they registered increases in wage incomes per hour worked higher than the percentage increase for labor productivity. Labor productivity towards the end of the analyzed period registers a path of economic development close to traditional economic theories.

If we were to make a comparison between the countries that registered a higher upward trend in the share of wage incomes compared to the countries that registered a trend within the limits of the economic theories or those that were more cautious and that did not offer increases of wage incomes per working-hour over the percentage of increased labor productivity should, in theory, be affected by inflation.

In the following table, the present paper analyzes the impact of the measures adopted by the private companies and governmental institutions in the 13 countries analyzed on the inflation rate index. Any wage increase, above or over labor productivity, should automatically generate inflation.

Table 3. HICP annual average rate of change

\begin{tabular}{|l|c|c|c|c|c|c|c|c|c|c|c|c|c|c|c|}
\hline GEO/TIME & $\mathbf{2 0 0 4}$ & $\mathbf{2 0 0 5}$ & $\mathbf{2 0 0 6}$ & $\mathbf{2 0 0 7}$ & $\mathbf{2 0 0 8}$ & $\mathbf{2 0 0 9}$ & $\mathbf{2 0 1 0}$ & $\mathbf{2 0 1 1}$ & $\mathbf{2 0 1 2}$ & $\mathbf{2 0 1 3}$ & $\mathbf{2 0 1 4}$ & $\mathbf{2 0 1 5}$ & $\mathbf{2 0 1 6}$ & $\mathbf{2 0 1 7}$ & $\mathbf{2 0 1 8}$ \\
\hline Bulgaria & 6,1 & 6,0 & 7,4 & 7,6 & 12,0 & 2,5 & 3,0 & 3,4 & 2,4 & 0,4 & $-1,6$ & $-1,1$ & $-1,3$ & 1,2 & 2,6 \\
\hline Czech Rep. & 2,6 & 1,6 & 2,1 & 2,9 & 6,3 & 0,6 & 1,2 & 2,2 & 3,5 & 1,4 & 0,4 & 0,3 & 0,6 & 2,4 & 2,0 \\
\hline Estonia & 3,0 & 4,1 & 4,4 & 6,7 & 10,6 & 0,2 & 2,7 & 5,1 & 4,2 & 3,2 & 0,5 & 0,1 & 0,8 & 3,7 & 3,4 \\
\hline Croatia & 2,1 & 3,0 & 3,3 & 2,7 & 5,8 & 2,2 & 1,1 & 2,2 & 3,4 & 2,3 & 0,2 & $-0,3$ & $-0,6$ & 1,3 & 1,6 \\
\hline Cyprus & 1,9 & 2,0 & 2,2 & 2,2 & 4,4 & 0,2 & 2,6 & 3,5 & 3,1 & 0,4 & $-0,3$ & $-1,5$ & $-1,2$ & 0,7 & 0,8 \\
\hline Latvia & 6,2 & 6,9 & 6,6 & 10,1 & 15,3 & 3,3 & $-1,2$ & 4,2 & 2,3 & 0,0 & 0,7 & 0,2 & 0,1 & 2,9 & 2,6 \\
\hline Lithuania & 1,2 & 2,7 & 3,8 & 5,8 & 11,1 & 4,2 & 1,2 & 4,1 & 3,2 & 1,2 & 0,2 & $-0,7$ & 0,7 & 3,7 & 2,5 \\
\hline Hungary & 6,8 & 3,5 & 4,0 & 7,9 & 6,0 & 4,0 & 4,7 & 3,9 & 5,7 & 1,7 & 0,0 & 0,1 & 0,4 & 2,4 & 2,9 \\
\hline Malta & 2,7 & 2,5 & 2,6 & 0,7 & 4,7 & 1,8 & 2,0 & 2,5 & 3,2 & 1,0 & 0,8 & 1,2 & 0,9 & 1,3 & 1,7 \\
\hline Poland & 3,6 & 2,2 & 1,3 & 2,6 & 4,2 & 4,0 & 2,6 & 3,9 & 3,7 & 0,8 & 0,1 & $-0,7$ & $-0,2$ & 1,6 & 1,2 \\
\hline Romania & 11,9 & 9,1 & 6,6 & 4,9 & 7,9 & 5,6 & 6,1 & 5,8 & 3,4 & 3,2 & 1,4 & $-0,4$ & $-1,1$ & 1,1 & 4,1 \\
\hline Slovenia & 3,7 & 2,4 & 2,5 & 3,8 & 5,5 & 0,8 & 2,1 & 2,1 & 2,8 & 1,9 & 0,4 & $-0,8$ & $-0,2$ & 1,6 & 1,9 \\
\hline Slovakia & 7,5 & 2,8 & 4,3 & 1,9 & 3,9 & 0,9 & 0,7 & 4,1 & 3,7 & 1,5 & $-0,1$ & $-0,3$ & $-0,5$ & 1,4 & 2,5 \\
\hline
\end{tabular}

Source: Eurostat

However, what can be observed in the previous table is the fact that all the analyzed countries are experiencing a decline in the inflation rate since 2011, 2012 and even continuing to register deflation starting in 2014, continuing in 2015, 2016.

Starting with 2017, all the countries analyzed begin to register inflation again, but at a lower level. Only Romania and Estonia at the end of 2018 had an inflation rate above 3\%, Romania marking $4.1 \%$ and Estonia registering 3.4\%. The rest of the analyzed countries recorded percentages lower than for these two cases. 
If we compute the average of the harmonized index of consumer prices of the 13 countries, the final value is $2.3 \%$, which is not significant. Furthermore, all the 13 analyzed countries have inflation targeting measures and they all stick to figures that can have a depreciation or appreciation effect. For example, Romania's inflation target is $2.5 \%$ but the depreciation or appreciation effect of inflation must be kept in a $\pm 1 \%$. The $4.1 \%$ is close to the $2.5 \%$ established by the Romanian central bank. For sure the rest of the 12 analyzed countries have inflation targeting measures themselves.

From the analyses carried out, there is no link between the percentage of wage increase, the percentage of labor productivity growth and their impact on the inflation rate index.

\section{CONCLUSION}

Raising wages without real support from increased labor productivity shows that it does not have a devastating impact on the harmonized index of consumer prices. As can be seen in the study carried out, especially in table 3 , the evolution of the harmonized index of consumer prices is a smooth, predictable one, without any special jumps that will cause imbalances in the 13 analyzed economies.

All the 13 analyzed countries record the harmonized index of consumer prices below the value of $4 \%$, only Romania being the only country with a value of $4.1 \%$. If we compute the average of the harmonized index of consumer prices of the 13 countries, the final value is $2.3 \%$, which is not significant. Furthermore, if we take into consideration the harmonized index of consumer prices of $2 \%$ targeted by the European Central Bank and take it as a benchmark, one can conclude that the deviation from this target is not a severe one.

The correlation between wage growth and labor productivity must remain valid in the future, but this future should not be viewed with fear as to the effects that a disproportionate increase in pay relative to labor productivity will have on the harmonized index of consumer prices.

The paper emphasizes that the impact in the 13 countries analyzed is a minimal one, which can be kept under control by the central banks of the respective countries through sustainable monetary policy measures and prudent fiscal policy.

\section{REFERENCES}

Gordon, R. (1986) Productivity, wages, and prices inside and outside of manufacturing in the U.S., Japan, and Europe, National Bureau of Economic Research

Hellerstein J., Neumark D., Troske K. (1996) Wages, productivity, and worker characteristics: evidence from plant-level production functions and wage equations, National Bureau of Economic Research

Biesebroeck Van J. (2003) Wages equal productivity. Fact or fiction? National Bureau Of Economic Research

Faggio G., Salvanes K., Reenen Van J. (2007) The evolution of inequality in productivity and wages: panel data evidence, National Bureau of Economic Research

Feldstein M. (2008) Did wages reflect growth in productivity? National Bureau of Economic Research

Stansbury A., Summers L. (2017) Productivity and pay: is the link broken? National Bureau of Economic Research

Lazear E. (2019) Productivity and wages: common factors and idiosyncrasies across countries and industries, National Bureau of Economic Research 